Kocatepe Tip Dergisi

Kocatepe Medical Journal

16: 57-66/Ocak 2015

DERLEME / REVIEW

\title{
Diyabetik Retinopati ve Nitrik Oksit
}

\section{Diabetic Retinopathy and Nitric Oxide}

\author{
Sibel INAN \\ Afyon Devlet Hastanesi Göz Hastalıkları Kliniği, Afyonkarahisar
}

Geliş Tarihi / Received: 30.04.2012

Kabul Tarihi / Accepted: 22.05.2012

\section{ÖZET}

Erişkin körlüğünün en önemli nedenlerinden birisi patogenezi tam olarak açıklanamamış diyabetik retinopatidir. Diyabetik retinopati patogenezinin anlaşılması daha iyi tedavisine ön ayak olabilir. Diyabetik retinopatide vasküler hasar ön plandadır. Endotelin vasküler tonus ve yapının korunmasında önemli rolü olduğuna ilişkin kanıtlar vardır. Endotel türevi vazoaktif mediatörlerden en önemlilerinden biri nitrik oksittir. Nitrik oksit vasküler düz kas hücrelerinin antiproliferatif düzenlenmesinde anahtar role sahip çok fonksiyonlu bir moleküldür. Diabetik retinopati patogenezinde nitrik oksitin de rolü olabileceği savunulmaktadır.

Nitrik oksit sentezi yapan üç tür NOS izoenzimi vardır. Bunların içinden temel olarak vasküler endotelde bulunmakta olan izoenzim, endotelial-NOS (eNOS) olarak adlandırılır. eNOS endotel fonksiyonunun korunmasında gereklidir . Retinanın proliferatif hastalıklarında nitrik oksidin rolü olabileceği, nitrik oksidin hücre büyümesini kontrol edebileceği bildirilmiştir. Bu açıdan diyabetin mikrovasküler komplikasyonlarının belirlenmesinde eNOS ilgi çekici görünmektedir. eNOS geninde çeşitli polimorfizmler tanımlanmıştır. Özellikle promotor bölgesindeki T-786C, 4. intron bölgesinde 27-bp tekrarı ve 7. eksondaki Glu298Asp dikkat çekmiştir. Endoteliyal NOS gen polimorfizm ile ilgili olarak retinadaki defektif eNOS ekspresyonu özellikle diabetik makula ödemi gelişimine katkıda bulunabilmektedir. Çalışmalardaki farklılıklar diyabetik retinopati ile eNOS gen polimorfizmi arasındaki ilişkinin coğrafik ve etnik farklılıklara göre değişebildiğini göstermektedir. Bu makalede NO ve ilgili gen polimorfizmlerinin diabetik retinopati patogenezindeki önemi gözden geçirilmeye çalışılmıştır.

Yazışma Adresi / Correspondence: Uzm. Dr. Sibel iNAN

Dumlupınar Mh Turabi Cd. Tütüncü Apt B Blok

4/7 03200 Afyonkarahisar

E-Posta: drinan33@gmail.com
Anahtar Kelimeler: Diyabetik Retinopati, Patogenez, Nitrik Oksit, eNOS, Gen Polimorfizmi

\section{ABSTRACT}

One of the most important cause of blindness in developed or developing countries is diabetic retinopathy, of which pathogenesis has not been yet clarified exactly. Understanding of pathogenesis of DRP can cause better management of this disease. Vascular damage is leading pathology in diabetic retinopathy. There is some proof that endothelin has important role in maintenance of vascular tonus and structure. Nitric oxide (NO) is one of the most important vasoactive mediators derived from endothelium. Nitric oxide is multifunctional molecule having key role on the anti-proliferative regulation of vascular smooth muscle cells. It has also been suggested that nitric oxide can play a role in the pathogenesis of diabetic retinopathy.

There are three nitric oxide synthase (NOS) isoenzymes producing NO. Out of them, the isoenzyme present essentially in vascular endothelium is called as endothelialNOS (eNOS) and needed to protect endothelial functions. It has been reported that NO can control cellular growth and play role in the retinal pathologies due to proliferative retinal diseases. From this respect, eNOS appears to be an interesting molecule in the identification of microvascular complications of diabetes. Various polymorphisms have also been identified in the eNOS gene. The T-786C polymorphism located in promoter region of eNOS gene, 27-bp duplication in intron 4 region and Glu298Asp in exon 7 have been attracting attention. Defective retinal eNOS expression related to its polymorphisms may contribute to the development of macular edema. Differences among the studies may demonstrate that a relationship between diabetic retinopathy and eNOS gene polymorphism can vary due to geographic and ethnic differences. Importance of NO 
and relevant gene polymorphisms in the pathogenesis of diabetic retinopathy has been reviewed in this article.

Key Words: Diabetic retinopathy, pathogenesis, Nitric Oxide, eNOS, gene polymorphisms

\section{Giriş}

Diabetik retinopati( $D R)$ günümüzde gelişmiş ülkelerde tüm yaş grupları içinde yaşa bağlı makula dejenerasyonundan sonra ikinci, üretken çağdaki nüfus içinde ise birinci sırada körlük nedenidir. Tanının konmasından sonra $15 \mathrm{yıl}$ içinde birçok hastada diabetik retinopati proliferatif evreye ulaşmaktadır.

DR'nin patogenezi hala tam olarak açıklanabilmiş değildir, birçok araştırma halen devam etmektedir. Diabetes mellitusun göze ait komplikasyonlarının tedavisinde medikal tedaviye ek olarak, cerrahi tedavi de yapılmaktadır. Pars plana vitrektomi diabetik retinopati komplikasyonlarının tedavisinde en sık uygulanan cerrahi tedavidir (1).

DR gelişen hastalarda antioksidan savunmanın bozulduğu, serbest radikallerin arttğı ve lipit peroksidayon ürünlerinin diabetik retinopatinin vasküler hasarından sorumlu olabileceğinden söz edilmektedir (2). Bunlara ek olarak son yıllarda birçok hastalığın patogenezinde rolü olduğu kanıtlanan nitrik oksidin (NO) proliferatif vitreoretinal hastalıklarda da rol alabileceği savunulmaktadır. Özellikle nitrik oksit sentaz-II enzimi tarafindan oluşturulan NO'in in vivo ve in vitro çalışmalarda sitokinler tarafindan kontrol edildiği ve oluşan NO'in lipit peroksit ürünlerine dönüştüğü gösterilmiştir. Organizmada fizyolojik birçok olayda NO'in faydalı etkileri olmakla birlikte zararlı etkileri de olabilir $(3,4)$. Vasküler tonüs ve yapının korunmasında endotelin önemli rolü olduğuna dair kanıtlar vardır. En önemli endotel türevi vazoaktif mediatörlerden biri NO'tir (5). NO, vasküler ve kardiyak kasılmayı azaltan ana düzenleyicidir (6). NO bu etkilerini guanilat siklaz üzerinden, hedef hücrede cGMP konsantrasyonunu artırarak gösterir (7).

Diabetik retinopati erişkin körlüğünün en sık nedeni olarak gösterilmektedir (9). Ek olarak diabetik retinopatinin herhangi bir evresinde görülen diabetik makülopati veya makula ödemi görsel bozulmanın en önemli nedenidir $(9,10)$. Makula ödeminin gelişmesinde en önemli rolü oynayan patofizyolojik basamak kan-retina bariyerinin bozulmasıdır $(10,11)$. Hem retinal kapiller endotel hücreleri tarafindan oluşturulan iç bariyer hem de retinal pigment epitel hücrelerinin sıkı bağlantılarıyla oluşan dış bariyer makula ödeminin gelişimi sırasında etkilenebilir. NO vasküler tonüs ve vasküler düz kas hücrelerinin antiproliferatif düzenlenmesinde anahtar role sahip çok fonksiyonlu bir moleküldür $(12,13)$. iNOS tarafindan üretilen yüksek miktarlardaki NO, toksik ve hasar yapıcı olarak gösterilse de yapısal olarak düşük düzeyde NO sağlayan eNOS endotel fonksiyonunun korunmasında gereklidir (13). Dolayısıyla diyabetin mikrovasküler komplikasyonlarının ve de kardiyovasküler hastalığa yatkınlığın belirlenmesinde eNOS ilgi çekici görünmektedir. eNOS geninde çeşitli polimorfizmler tanımlanmıştır $(14,15)$. Özellikle promotor bölgesindeki T-786C, 4. intron bölgesinde 27-bp tekrarı ve 7. eksondaki Glu298Asp dikkat çekmiştir. Tip I DM'da 27-bp tekrarının 'b' aleli yüksek diabetik retinopati riski ile ilişkili bulunmuştur $(16,17)$. Tip II DM'lu hasta grubunda eNOS gen polimorfizmi (T-786C, promotor bölgede ve intron 4 deki 27bp tekrarı) makula ödeminin oluşumu ile direkt ilişkili bulunmuştur. Daha önceki çalışma sonuçları ile göz önüne alındığında polimorfizm ile ilgili retinadaki defektif eNOS ekspresyonu makula ödemi gelişimine katkıda bulunabilir (18).

\section{NiTRIK OKSіт}

NO fiziksel olarak gaz yapıda bulunan, çoğu hücrede enzimatik olarak sentezlenen, hücre içinde plazma membran proteinlerini aktive ederek sekonder haberci olarak davranan, hücreler arasında bilgi taşıyan ve parakrin etki gösteren mediatördür. Etkisi sonucu vasküler tonüs değişmesi, nörotransmisyon, immün sitotoksisite ve birçok biyolojik ve biyokimyasal olay gerçekleşir. NO'in gözde fizyolojik ve patofizyolojik rolü olduğunu gösteren veriler mevcuttur. NO sentezinin inhibe edilmesi ve NO donörlerinin oftalmolojide tedavi edici etkileri olabileceğinden bahsedilmektedir $(3,19)$.

\section{Nitrik Oksit Sentezi}

NO, L-argininin L-sitrülline dönüşmesi sırasında ortaya çıkar. Bu enzimatik yolu nitrik oksit sentaz (NOS) kontrol eder. Diğer nörotransmitterler gibi NO konvansiyonel regülatör mekanizmalarla salgılanmaz 
ve depolanmaz, bu nedenle NO biyosentezinin kontrolü önem taşımaktadır (20)

Nitrik oksit sentaz'ın (NOS) en az 3 izoenzimi vardır:

1- İndüklenebilir NOS (iNOS): Makrofajlarda bulunur. Patolojik olaylarda görev alır.

2- Yapısal nöronal NOS (nNOS): Beyinde bulunur.

3-Yapısal endotelyal NOS (eNOS): Farklı kromozomlarda bulunan gen ailesince oluşturulur ve farklı hücrelerden sentezlenir (8).

N-mono-metil-L-arginin (L-NMMA), N-nitro-Largininnemetil ester (L-NAME ) ve $\mathrm{N}$-nitro-L-arginin (L-NA), gibi bazı L-arginin analogları NO sentezini inhibe eder. Son zamanlarda NOS inhibitörü olarak tanımlanmış, farklı etki mekanizmaları ile NO sentezini inhibe eden aminoguanidin, nitroindazol, izothioüre gibi nonaminokaid ajanlar ve thiositrüllin, $\mathrm{N}$-iminoetillisin gibi ajanlar tanımlanmıştır.

\section{Nitrik Oksit ve Retina}

NOS, sinirlerde pre ve post sinaptik olarak bulunur. Retinada farklı çalışmalara göre NO'in nöronal iletide (nörotransmisyon), horizontal hücrelerde elektriksel eşleşme, bipolar hücrelerde cGMP aktivasyonu ve gangliyon hücrelerinde cGMP aracılı iletinin kontrolünde görev aldığı gösterilmiştir. Işığın nöral sinyallere dönüştürme işlemi olan fototransdüksiyonda, NO fotoreseptörlerdeki bazı iyon kanallarında ileti değişikliği yaparak görsel işleve katkıda bulunur $(20,22)$.

Retina iskemisinde NO'nun patogeneze olan katkıları tartışmalıdır. Yeni araştırmalar NO'in iskemik hasar mekanizmasında etkilenen önemli bir ajan olduğunu, serbest radikal üretilmesi ile nöronal hücre ölümünü kolaylaştırdığını ve N-metil-D-aspartat-reseptör aracılı toksisiteye neden olduğunu bildirmektedirler. Retina iskemik dönem esnasında hasar görür, ancak iskemiden sonra paradoksal olarak serbest oksijen radikalleri oluşabilir. İskemiden sonra retinada süperoksit anyon varlığı bunun kanıtıdır, oluşan serbest radikaller NO ile birleşip peroksinitrit oluşturabilir. $\mathrm{Bu}$ nedenle farklı serbest radikallerin kombinasyonu retinada iskemi sonrası reperfüzyonda hücrelere toksik etki gösterebilir. Bununla birlikte NO, iskemi esnasında veya iskemiden hemen sonra kan akımını düzeltmeye, hasarlı doku miktarını azaltmaya çalışmaktadır (21).

\section{Vitreoretinal Proliferasyon ve Nitrik Oksit}

In vitro ortamda NO'in RPE hücre proliferasyonunu inhibe ettiği gösterilmiştir. Nitrik oksit donörlerinin verilmesiyle veya lipopolisakkarid ve sitokin uyarısı ile endojen olarak NO elde edilmektedir. Proliferatif retinal hastalıklarda RPE hücre proliferasyonuyla birlikte olan retina patolojilerinde NO'in rolü olabileceği, hatta NO'in hücre büyümesini kontrol edebileceği bildirilmiştir. Proliferatif vitreoretinopatili (PVR) hastalardan elde edilen vitreus örneklerindeki NO düzeyi ile hastalık arasındaki ilişkinin, PVR patolojisinin (enflamasyon, hücre proliferasyonu) anlaşılmasında önemli olabileceği vurgulanmaktadır.

Retinada NO'in primer kaynağının Müller hücreleri veya RPE hücreleri veya gözü infiltre eden makrofajlar olup olmadığı bilinmemektedir. NO, oksijen türevleri ile birleşebilen serbest radikalleri etkileyebilir ve yüksek sitotoksisitesi olan peroksinitrit anyonu oluşturur. RPE ve nöroretinayı etkileyen metabolik hastalıklardan sonra ışık algılaması, karanlık adaptasyonu, kontrast duyarlılık ve renk görme patogenezinde NO rol oynayabilir $(21,23)$.

\section{Nitrik Oksitin Gen haritasındaki Lokusu : 7q36}

Nitrik oksit, endotel kaynaklı gevşeme faktörünün (endothelium-derived relaxing factor, EDRF) biyolojik aktivesinden sorumludur (24,25). EDRF, düz kas salınımını ve trombosit birikimini engelleyerek, vazomotor tonüsün ve kan akışının düzenlenmesinde önemlidir. Janssens ve ark., insan vasküler nitrik oksit sentazı kodlayan bir cDNA izole etti. Translasyonu bitmiş bu insan proteini 1294 amino asit uzunluğundaydı ve beyindeki NOS ile, aminoasit sekansının \%52'si ortakt (26). eNOS geni, 21 kilobazlık bir genomik DNA'ya yayılıp, 26 eksondan oluşmakta ve 4052 nükleotidlik bir mRNA' yı kodlamaktadır. NO'in pek çok sistemdeki önemli fizyolojik düzenleyici fonksiyonu göz önüne alınarak Science dergisi tarafindan 1992'de 'yılın molekülü' seçilmiştir (27). Insanlarda, 3 farklı NOS izoenzimini kodlayan 3 farklı genin varlığı tanımlanmıştır; nNOS izoformunu kodlayan gen 12 . kromozomda, iNOS'u kodlayan gen 17. kromozomda ve eNOS'u kodlayan gen 7. kromozomda tespit edilmiştir (28). Endotel hücre kültürlerinde eNOS aktivitesi protein kinaz C (PKC) tarafindan düzenlenmektedir. PKC nin aktivasyonu NO salınımının azalmasına neden olurken, PKC inhibisyonu eNOS aktivitesini arttırır (29). Yarı ömrü birkaç saniye kadar kısa olan 
NO, biyolojik membranlardan kolayca diffüze olabilir. Son yörüngesindeki eşleşmemiş elektron sayesinde ortamda bulunan diğer serbest radikallerle çok kısa süre içinde reaksiyona girebilir (27)

Diabetik retinopatinin bazı bireylerde çok hızlı ilerleme gösterirken bazı bireylerde sakin seyretmesi, retinopati gelişimi ve ilerlemesinde kan şeker düzeyi dışında başka faktörlerin de rol oynadığını düşündürmektedir. Ilerlemede multifaktöryel etkenler etkili olsa da son yıllarda genetik faktörlerin başlıca rol oynadığı düşünülmekte ve bu yönde çeşitli çalışmalar yapılmaktadır. Genetik çalışmalarda diabetik retinopatinin patogenezinde rol oynayan biyokimyasal mekanizmalara katilan maddelerin kromozomlardaki genetik şekil değişiklikleri araştrılmaktadır. Bu maddelerden birisi de nitrik oksittir. Son yıllarda nitrik oksitin sistemik hastalıklardaki rolü ile ilgili çok sayıda araştırma yapılmaktadır. Nitrik oksitin etiyopatogenezinde rol aldığı en önemli hastalıklardan birisi diabetes mellitusdur. Diabetes mellitusun en önemli komplikasyonlarından biri olan diabetik retinopati erişkin körlüğünün en sık nedeni olarak gösterilmektedir (9). Ek olarak diabetik retinopatinin herhangi bir evresinde görülen diabetik makulopati veya makula ödemi görsel bozulmanın en önemli nedenidir (9-11).

Genellikle hiperglisemi, kötü metabolik kontrol, sitokinler, vazoaktif hormonlar ve insüline direnç diabetik mikrovasküler hastalıkta ilerlemeden sorumlu faktörlerdir. Artmış kan akımı, retinal perisitlerin selektif kaybı, bazal membran kalınlaşması, endotelyal hücre kaybı ve küçük kapillerlerin tıkanması birbirlerini tamamlayıcı etki ile retinopatiye yol açarlar (30). "Diabet Kontrol ve Komplikasyonları Çalışma Grubu" araştırması diabetik hastalarda retinopatinin başlamasında genetik faktörlerin etkili olduğunu göstermiştir (31).

NO oldukça reaktif bir intersellüler sinyal molekülü olup antitrombojenik ve antiplatelet regülatuar aktivitelerine ek olarak vasküler tonüs ve vasküler düz kas hücrelerinin antiproliferatif düzenlenmesinde de anahtar role sahip çok fonksiyonlu bir moleküldür (1213)

Daha önce birçok aday genlerin diabetik retinopati ile ilişkili olduğu belirtilmiştir. Özellikle aldoz reduktaz enzimi geni detaylı bir şekilde araştırıımış ve $5^{\prime}$ bölgesindeki ve C-106T dinukleotid polimorfizminin diabetik retinopati ile direk ilişkili oldukları tespit edilmiştir. Bazı çalışmalarda VEGFün $5^{\prime}$ kodlanmamış bölgesinde C-634G olarak tanımlanan genel bir polimorfizmin diabetik retinopati mevcudiyeti ile doğrudan ilişkili olduğu ve fonksiyonel olarak önemli olduğu sonucuna varılmıştr. eNOS geninde çeşitli polimorfizmler tanımlanmıştır (14-15).Tip I DM' da 27bp tekrarının 'b' alleli yüksek diabetik retinopati riski ile ilişkili bulunmuştur $(16,17)$.

Vücutta vasküler düz kas ve kalp kası dahil değişik dokular diğer 2 proteine kıyasla büyük miktarda iNOS üretimi yapar. iNOS tümör nekroz faktör ve İL 1 gibi sitokinler tarafindan indüklenir. iNOSun sitokinlere cevap olarak üretimi enflamatuar cevabın bir parçasıdır ve doku hasarına yol açan vazodilatasyon vasküler sızıntiya katkıda bulunur, bu durum oküler anjiyogenezisin regülasyonundaki muhtemel rolünü de akla getirir (32). Dolayısıyla oluşan nitrik oksit, VEGF dahil vazodilatatör peptidlerin büyümeyi arttrıcı etkisini uyaran potent anjiyojenik bir mediatör olarak davranabilir (33).

Tüm faktörlerin iNOSun diabetik retinopatideki önemli rolü olabileceğini düşündürmesi nedeniyle değişik çalışmalarda iNOS gen polimorfizmi çalışılıış̧ır. iNOS gen polimorfizminin Kuzey İrlanda toplumunda diabetik retinopati ile ilişkisi bildirilmiştir (30).

Nitrik oksit üretimini, vazodilatasyon ve dolayısıyla iskelet kaslarına glikoz ve insülin ulaşımını arttırır. NO aynı zamanda hepatik glikoz metabolizmasında da rol oynar (34). Bununla birlikte tip II DMli hastaların insüline dirençli birinci derece akrabalarında NO aracılığıyla gerçekleşen cGMP üretiminin azalmış olduğu gösterilmiştir (35). Tanımlanmış olan eNOS gen polimorfizmleri arasında promotor bölgede T786C polimorfizminin (- T786C), intron 4' de 27 baz çifti tekrarının (in4a/ b) ve ekson 7 deki G894T polimorfizminin (G894T) NO seviyelerini etkilediği bildirilmiştir $(36,37)$. eNOS gen zinciri 1993'te ortaya çıkarılmış ve kromozom 7q35-36 da haritalandırıımıştır. Gen, 1203 aminoasit içeren 135-kDa bir proteini kodlayan 26 eksondan oluşmaktadır.

Retinopati geliştirilmiş rat retinalarında artmış nitrik oksit sentaz aktivitesi gözlenmiştir (38). Diabetik retinopatinin önlenmesinde ve gecikmesinde önemli rolü olan perisitler anjiogenezisin potent inhibitörü olan çözünür proteinler salarlar ve iNOS'u down regüle ederek hareket ederler (39). Retinopati gelişen tip I 
diabet hastaları endotelyal disfonksiyonun göstergesi olarak artmış nitrik oksit sentaz aktivitesine sahiptirler (40). Nitrik oksit sentazın inhibisyonu gözü iskemik değişikliklerden korur. Bu da potansiyel terapötik yaklaşımları akla getirir. Aminoguanidin tedavisi deneysel ratlarda yapılan çalışmalarda diabetik retinopati gelişmesini inhibe etmiştir. Bulgular bu ilacın aşırı nitrik oksit üretiminden sorumlu sitokinlerce indüklenen nitrik oksit sentaz izoformunu selektif olarak bloke ettiğini göstermektedir (41).

iNOS gen polimorfizminin diabetik retinopati ile ilişkisini araştıran bir çalışmada iNOS geninin 210bp alelinin diabetik retinopati gelişimi için risk aleli olduğu, 200 ve $220 \mathrm{bp}$ alellerinin ise retinopati ve retinopatinin komplikasyonlarının gelişmesi açısından (proliferatif diabetik retinopati, diabetik makulopati) koruyucu olduğu bildirilmiştir (42).

G894T eNOS gen varyantının eNOS proteini üzerine fonksiyonel etkileri olduğu bildirilmiştir. Bu polimorfizm NOS enziminin subselüler trafiğini kontrol eden şaperon proteinleriyle ve enzimin parçalanma sürecinde yer alan proteinlerle protein- protein etkileşimlerini içerir (43).

Yüksek glikoz konsantrasyonlarında NO üretiminin arttı̆̆ ya da azaldığı bildirilmiştir. Artmış veya sıklıkla azalmış NO mevcudiyeti klinik ve deneysel durumlarda diabetik komplikasyonlarla ilintili bulunup NO'nun dual fonksiyonu olabileceğini düşündürmektedir (44). Kronik hiperglisemi uzun süreli birçok hastada şiddetli olmayan diabetik retinopatiye yol açsa da hastaların çoğunda ciddi diabetik retinopati oluşturmak için yeterli değildir. Bu durum genetik faktörlerin potansiyel ilave rolünü düşündürmektedir (45). Bu hipotez "Diabetes Control and Trial (DCCT)" tarafindan çalışılmış ve ciddi diabetik retinopatili hastalarda güçlü ailesel retinopati geçişi olduğu, ancak şiddetli retinopatisi olmayanlarda böyle bir geçişin olmadığı gösterilmiştir (31).

NO'nun retinaya aşırı salınımı direkt ya da indirekt olarak oksidatif hasarı, iskemiyi ve neoanjiyogenezisi indükler; bu da NO'nun diabetik retinopatinin gelişiminde ve şiddetinde önemli bir patojenik rolü olduğunu düşündürür. Bunu düşündüren bulgulardan bazıları şunlardır; 1- NO'in aşırı üretimi retinal endotelyal ve glomerül hücrelerinde oksidatif strese yol açabilir. 2- Diabetik retinopatinin gelişimine öncülük eden perisitlerin kaybı ve retinal yataktaki artmış kan akımı kısmen nitrik oksidin aşırı üretimine bağlı olabilir (46).

Diabetik hastalarda şiddetli diabetik retinopati riski oksidatif stres belirteçlerinin varlığıyla ilişkili bulunmuştur (47). İntravenöz VEGF infüzyonu endotelyal hücre bariyerinin fonksiyonel bütünlüğünü akut olarak bozabilir ve NOS aktivasyonunu içeren bir mekanizma aracılığıyla oküler dokulardaki arterioler direnci azaltır (48). VEGF'in yol açtığı anjiyogenezis ve vasküler permeabilite artışı eNOS'dan yoksun bırakılan farelerde engellenmiştir. Yine benzer bir diabetik retinopati modeli olarak eNOS'dan yoksun fare ve bir NOS inhibitörü olan N-nitro-I- arginin ( I- NNA) ile tedavi edilmiş fare modelinde vazoobliterasyonda ve vitreus neovaskülarizasyonunda anlamlı bir azalma gösterilmiştir (49). Daha yeni bir çalışmada iNOS salınımının inhibisyonunun avasküler retinada lokal olarak anjiyogenezisi inhibe ettiği gösterilmiştir. Bu fenomene VEGF reseptörünün down regülasyonunun en azından kısmen aracılık ettiği düşünülmüştür. $\mathrm{Bu}$ konuda önemli olan diğer nokta ise iNOS eksprese eden hayvanlarda patolojik intravitreal neovaskülarizasyonun kayda değer bir şekilde daha güçlü olduğudur (50).

Bazı bulgular retinada bozulmuş olan eNOS ekspresyonunun kan-retina bariyerinin bozulmasında önemli rol oynadığını, makuler ödem gelişimine katkıda bulunabileceğini düşündürmektedir. İmmün cevap ve enflamasyon gibi patolojik süreçlerde iNOS tarafindan üretilen yüksek NO düzeyleri vücut için zararlı olsa da, düzeyi eNOS tarafindan devam ettirilen fizyolojik konsantrasyonlardaki NO'nun vasküler endotel için koruyucu özelliği olabilir (13). Dolayısıyla eNOS'daki bozulma hiperglisemi veya hipertansiyonun neden olduğu endotelyal hücre hasarını daha da hızlandırarak endotel hücrelerinin oluşturduğu iç kan retina bariyerinin bozulmasına yol açabilir. Dahası, bozulmuş eNOS aktivitesi vasküler tonüsün regülasyonunu uyararak hipoksiyle sonuçlanabilir ve VEGF tarafindan indüklenmiş vasküler permeabilite artışına neden olabilir. Bozulmuş bazal NO üretimi endotelyuma lökosit adezyonuna izin vererek kan- retina bariyerinin bozulmasına ve kapiller nonperfüzyona yol açabilir (51-52). Alternatif olarak bozulmuş eNOS aktivitesi doğrudan mikrovasküler permeabiliteyi arttrabilir (53-54). İlginç olarak eNOS, kan-retina bariyerinin sürdürülmesinde önemli olduğu bilinen Müller 
hücrelerinde lokalizedir (55). Awata ve ark. eNOS gen polimorfizminin (promotor bölgedeki T786C ve intron 4'deki 27bp tekrarı ) tip II DMli Japon hastalarda makula ödemi ile ilişkili olduğunu bildirmişlerdir (56). Retinadaki defektif eNOS ekspresyonunun makula ödemi gelişimine katkıda bulunuyor olabilir. Ancak Awata ve ark. diğer 2 polimorfizminin makuler ödemle ilişkisini bildirmiş olmalarına rağmen G894T polimorfizmiyle diabetik makula ödemi arasında ilişki bulamamıştr. Awata ve ark. eNOS ile ilgili çalışmış oldukları her 3 polimorfizmin diabetik retinopati ile ilişkili olmadıklarını bildirmişlerdir (56).

Taverna ve ark. daha yakın zamanda yaptıkları diğer bir çalışmada eNOS geninin diğer 2 polimorfizminin (T786C ve C774T) ciddi diabetik retinopati üzerine etkisi olmadığını bulmuşlardır (57). Ancak yazarlar, C786C taşıyıcılarının T786T ve T786C taşıyıcılarından sırasıyla 5 yıl ve 3,5 yıl daha önce panretinal fotokoagülasyon ile tedavi edildiklerini gözlemişlerdir. Dahası, bu ilişki HbA1C'nin \%8'in üstünde olduğu hastalarda daha belirgindir. Öte yandan T774T taşıyıcıları, C774C ve C774T taşıyıcılarından 6 yıl sonra panretinal fotokoagülasyon tedavisine intiyaç duymuşlardır (56). Tüm bu bilgiler eNOS genindeki polimorfizm farklılıklarının hastalarda diabetik retinopatinin şiddetini etkileyebileceğini göstermektedir.

Avustralya'da yapılan bir çalışmada 574 tip II DM'li hastada G894T mutasyonunun diyabetin vasküler komplikasyonlarıyla ilişkisi araştrılmış ve herhangi bir ilişki bulunamamıştır. G894T mutasyonu makrovasküler ve mikrovasküler komplikasyonlarla ilişkili bulunmadığı gibi aterojenik risk faktörleriyle de ilişkili bulunmamıştır (58).

Tso ve ark., NOS un her 3 polimorfizminin glikoz toleransı bozuk olan kişilerde uzun süreli glisemik sonuç ile ilişkisini araştırmışlardır (59). Glikoz toleransı bozuk olan 256 Çinli olgunun eNOS genotipleri belirlendikten sonra 5 yıl boyunca glisemik düzeyleri takip edilmiş ve 5 . yılda olguların \%40.2'sinde normal glikoz toleransı saptanırken $\% 39$ 'unda bozulmuş glikoz toleransı / açlık kan glikozu devam etmiş \%19.9unda ise DM gelişmiştir. 5 yılda ekson 7 G894T polimorfizminin glisemik seyir üzerinde anlamlı gen etkisi gösterilmiştir. T894 taşıyıcıları GG olgularına kıyasla persistan hiperglisemiye sahiptirler. $T$ aleli mevcudiyeti persistan hiperglisemi için anlamlı risk faktörü olarak kalmıştr. Diğer 2 gen polimorfizmi ise
5 yıllık glisemik durum üzerinde anlamlı bir etkilerinin bulunmadığı bildirilmiştir. Bu çalışmada incelenen Çinli popülasyonda eNOS G894T polimorfizminin persistan hiperglisemi açısından belirleyici olduğu açıklanmaktadır.

Son 15 yılda insülin salgısı ve insülin direnci üzerinde NOin rolünün anlaşılması için önemli çabalar gösterilmiştir. Özellikle fizyolojik insülin salgısının modülatörü olarak NO'nun rolü yaygın şekilde değerlendirilmiştir (60). Ayrıca spesifik olarak iskelet kası mitokondrilerinde lokalize eNOS aktivasyonunun kas kan akımını arttırdığı insülinin majör substrat olan glikozun kas hücrelerine girişini arttırdığı bulunmuştur (61-62). Azalmış NO aktivitesi, hiperinsülinemi, insülin direnci ve artmış NO düzeyi gibi daha önceden bildirilmiş bir fenotip özelliği ile genotip varyant arasında bir ilişki olduğu doğrulanmaktadır. $(63,64)$. Monti ve ark. ilk kez hiperinsülinemi, insülin direnci ve tip II DMlu hastalar için yeni bir genetik duyarlılık faktörünü ortaya koyacak şekilde G894T polimorfizmi ile tip II DM arasında anlamlı bir ilişki tanımlamışlardır. Bununla birlikte makroanjiopati prevalansının yüksek olduğu tip II DM'lu hasta popülasyonunda G894T polimorfizminin varlığı değerlendirildiğinde diabetik hastalarla kontrol bireyleri arasında alel frekansı açısından fark bulunamamıştır (65).

Fransada yapılan bir çalışmada Taverna ve ark., eNOS 4 polimorfizmi ve şiddetli diabetik retinopati riski arasındaki ilişkiyi araştırmışlardır (16). Tip I DM hastalarında eNOS 4 a/a homozigot delesyonu ve onun 4a aleli şiddetli olmayan diabetik retinopati ile ilişkili (diabetik retinopatisi olmayan veya zemin retinopatisi olan) bulunurken eNOS4b/b ve onun $4 \mathrm{~b}$ aleli şiddetli diabetik retinopati (preproliferatif DR ve proliferatif DR) ile ilişkili bulunmuştur. eNOS 4a/a genotipi (homozigot delesyon) olanlarda plazma NO metabolit düzeyleri eNOS $4 \mathrm{~b} / \mathrm{b}$ veya eNOS $4 \mathrm{a} / \mathrm{b}$ (heterozigot) olan olgulardaki kan düzeyinden anlamlı olarak daha düşük olduğundan, yazarlar homozigot eNOS a/a saptanan 7 kontrolün şiddetli DR ile etkilenmemesinin düşük NO düzeyine bağlı olabileceğini iddia etmişlerdir. Bu hipotezlerin tersi varsayıldığında eNOS 4 b/b saptanan hastalar daha sıklıkla şiddetli DRden etkilenmişlerdir. Kromozom 7q35te eNOS lokusuna yakın bir gen, eNOS geninin kendisinden ziyade, şiddetli DR için düşük riske katkıda bulunacağı göz ardı edilemez. ilginç olarak diabetik retinopati için koruma ve duyarlılık 
alellerine sahip aldoz reduktaz geni eNOS lokusuna yakın yerleşmiştir (66).

Diyabetin süresi, HbA1c düzeyleri, HT ve albuminüri çalışma ve kontrol grupları arasında anlamlı olarak farklı iken regresyon analizinde eNOS 4a/a genotipinin diabetik retinopati üzerindeki riskinin bu değişkenler tarafindan etkilenmediği bulunmuştur. Çalışmada diyabeti olmayan kontrol grubu oluşturmamış olmalarına rağmen eNOS 4 polimorfizminin diabetik populasyon arasındaki dağııımı diğer çalışmalardaki popülasyonlarda gözlenenlere benzerlik göstermiştir (67-69). Anglosakson popülasyonunda yapılan bir çalışmada uzun süreli tip I diyabeti bulunan hastalarda intron 13 bölgesinde yerleşik başka bir eNOS polimorfizmi ile şiddetli DR arasında bir ilişki bulunamamıştır (70).

Diabetik mikrovasküler komplikasyonlar ile eNOS genleri arasındaki muhtemel ilişkiler üzerinde de çalışıımış, ancak bu ilişkiler tutarsız bulunmuştur. Taverna ve ark. ' $b$ ' alellerinin ve bb genotiplerinin şiddetli diabetik retinopati ile ilişkili olduklarını belirtmişlerdir (16). Benzer şekilde Frost ve ark. da , 27 bp tekrarının bb genotipinin DR ile ilişkili olduğunu ileri sürmüşlerdir (17). Ancak Neughabauer ve ark. ise DR ile 27 bp tekrarı arasında hiçbir ilişki bulamamıştr (67).

Tavakkoly-Bazzaz ve ark. 'a' alleli ile dengesiz bir bağlant içerisinde olan - $786 \mathrm{C}$ allelinin DR ile önemli derecede ilişkili olduğunu belirtmişlerdir (71). Chen ve ark. eNOS ile ilgili $4 a / b$ ve G894T gen polimorfizmini çalışmışlardır. 4 a/b polimorfizminin $\mathrm{b} / \mathrm{b}$ genotipinin 2.4 kat artmış diabetik retinopati riskine sahip olduğunu bildirmişlerdir. (72) Bununla birlikte Santos ve arkadaşları Brezilya halkında yaptıkları çalışmalarında eNOS gen polimorfizmlerinin diabetik retinopati patogenezinde rol oynadığı hipotezini destekleyen bulgular elde edememişlerdir. ( 73)

Cilensek ve ark. yakın zamanda yayınlanmış çalışmalarında eNOS genine ait 4b/4a ( 27 bp VNTR) gen polimorfizminin $4 a / 4 a$ genotipinin proliferatif diabetik retinopati için 3.4 kat artmış riske sahip olduğunu bildirmişlerdir (7). Hindistandan bildirilen çalışmalarda ise eNOS geninin 4 VNTR ve intron 4 polimorfizmlerinin diyabetik retinopati ile ilişkili olmadığı bildirilmiştir $(75,76)$. Bu çalışmalardaki farklılıklar eNOS gen polimorfizminin diabetik retinopati ile olan ilişkisinin coğrafik ve etnik farklılıklara göre değişkenlik gösterdikleri anlamına gelebilir.

Makula ödeminin gelişmesinde en önemli rol oynayan patofizyolojik basamak kan retina bariyerinin bozulmasıdır $(10,11)$. Hem retinal kapiller endotel hücreleri tarafindan oluşturulan iç bariyer hem de retinal pigment epitel hücrelerinin sıkı bağlantılarıyla oluşan dış bariyer makuler ödemin gelişimi sırasında etkilenebilir. NO, vasküler tonüs ve vasküler düz kas hücrelerinin antiproliferatif düzenlenmesinde anahtar role sahip çok fonksiyonlu bir moleküldür $(12,13)$. iNOS tarafindan üretilen yüksek miktarlardaki NO'nun toksik vehasaryapıcıolduğuiddiaedilse deyapısalolarakdüşük düzeyde NO sağlayan eNOS endotel fonksiyonunun korunmasında gereklidir (13). Dolayısıyla diyabetin mikrovasküler komplikasyonlarının ve kardiyovasküler hastalığa yatkınlığın belirlenmesinde eNOS ilgi çekici görünmektedir. Tip II DM' lu hasta grubunda eNOS gen polimorfizmi (ki bunlar T-786C, promotor bölgede ve intron 4 deki $27 \mathrm{bp}$ tekrarı) makuler ödem oluşumu ile doğrudan ilişkili bulunmuştur. Daha önceki çalışma sonuçları da göz önüne alındığında polimorfizmle ilgili olarak retinadaki defektif eNOS ekspresyonu, makuler ödem gelişimine katkıda bulunabilir (18).

Birçok çalışma göstermektedir ki retina içerisindeki eNOS ekspresyonunun bozulması ile kan retina bariyerinin parçalanması makula ödemi gelişimine katkıda bulunabilir. Bozulmuş eNOS aktivitesi vasküler tonüs regülasyonunu bozabilir ve ayrıca direk olarak mikrovasküler permeabiliteyi arttrabilir. Makula ödemi diabetik hastalarda görme azalmasının önemli bir sebebidir ve diabetik retinopatinin herhangi bir evresinde gelişebilir. Bu yüzden diabetik makula ödeminin ilerlemesine katkıda bulunan risk faktörlerinin ortaya konulması önemlidir. Bu açıdan makula ödemi gelişiminde gen polimorfizminin etkili olup olmadığının gösterilmesi değerli olabilir.

Polimorfizmler tek başlarına, fonksiyonel olarak risk artş̧ına neden olabilirler; ya da, birbirleri ile ilişkili fonksiyonel değişikliklerle beraber, beraberlerindeki genler için (linkage disequilibrium'da) bir marker olabilirler veya olası bir gen-çevre ilişkisinin, risk faktörü üzerinde etkisini yansıttyor olabilirler. Bu rolleri belirlemek için daha ileri çalışmalara gerek vardır. 


\section{KAYNAKLAR}

1. Smiddy WE, Flynn HW. Vitrectomy in the management of diabetic retinopathy. Surv Ophtalmol 1999;43:491-507.

2. Cerillo A, Bortolotti N, Motz E, Crescetini A, Lizzio S.,Russo A, Tonutti L, Taboga C. Meal-generated oxidative stress in type 2 diabetic patients. Diabetes Care 1998;21:1529-1533.

3. Becquet $F$, Courtois $Y$, Goyreau O. Nitric oxide in the eye: multifaceted roles and diverse outcomes. Surv Ophtalmol 1997;42:71-82.

4. Shimizu K, Wu GS, Sultana C, Karla VK, Rao NA. Stimulation of macrophages by retinal proteins: production of reactive nitrogen and oxygen metabolites. Invest Ophthalmol Vis Sci 1999;40:3215-3223.

5. Böger $\mathrm{RH}$. The emerging role of asymmetric dimethylarginine as a novel cardiovascular risk factor. Cardiovasc Res 2003;59:824-833.

6. Böger RH, Bode-Böger SM, Szuba A, Tangphao O, Tsao PS, Chan JR et al. Asymmetric dimethylarginine: a novel risk factor for endothelial dysfunction. Its role in hypercholesterolemia. Circulation 1998;98:1842-1847.

7. Nadaud S, Bonnardeaux A, Lathrop M, Soubrier F. Gene structure, polymorphism and mapping of the human endothelial nitric oxide synthase gene. Biochem Biophys Res Commun 1994;198:1027-1033.

8. Waldman SA, Murad F. Biochemical mechanisms underlying vascular smooth muscle relaxation: the guanylate cyclase- cyclic GMP system. J Cardiovasc Pharmacol 1988;12(Suppl 5) :15-18.

9. Ciulla TA, Amador AG, Zinman B. Diabetic retinopathy and macular edema: pathophysiology, screening, and novel therapies. Diabetes Care 2003;26:2653-2664.

10. Antcliff RJ, Marshall J. The pathogenesis of edema in diabetic maculopathy. Semin Ophtalmol 1999;14:223-232.

11. Pelzek C, Lim JI. Diabetic macular edema: review and update. Ophtalmol Clin North Am 2002;15:555-563.

12. Gross SS, Wolin MS: Nitric oxide: pathophysiological mechanisms. Annu Rev Physiol 1195;57:737-769.

13. Albrecht EW, Stegeman Ca, Heeringa P, Henning $\mathrm{RH}$, van Goor $\mathrm{H}$. Protective role of endothelial nitric oxide synthase. J Pathol 2003;199:8-17.

14. Miyamoto $\mathrm{Y}$, Saito $\mathrm{Y}$, Kajiyama $N$, et al. Endothelial nitric oxide synthase gene is positively associated with essential hypertension. Hypertension 1998;32:3-8.

15. Nakayama $M$, Yasue $H$, Yoshimura $M$, et al. T-786-C mutation in the 5 -flanking region of the endothelial nitric oxide synthase gene is associated with coronary spasm. Circulation 1999;99:2864-2870.
16. Taverna MJ, Sola A, Guyot-Argenton C, Pacher N, Bruzzo F, Chevalier A, Slama G, Reach G, Selam JL. eNOS4 polymorphism of the endothelial nitric oxide synthase predicts risk for severe diabetic retinopathy. Diabet Med 2002;19:240-245.

17. Frost D, Chitu J, Meyer M, Beischer W, Pfohl M. Endothelial nitric oxide synthase (ecNOS) $4 \mathrm{a} / \mathrm{b}$ gene polymorphism and carotid artery intimamedia thickness in type 1 diabetic patients. Exp Clin Endocrinol Diabetes 2003 ;111:12-15.

18. Takuya A, Tamotsu N, Hiroyuki I, et al. Endothelial nitric oxide synthase gene is associated with diabetic macular edema in type 2 diabetes. Diabetes Care 2004; 27:2184-2190.

19. Kröncke KD, Feshel K., Kolb-Bachofen V. Inducible nitric oxide synthase and its product nitric oxide, a small molecule with complex biological activities. Biol Chem 1995;376 (Supll):327-343.

20. Ahmad I, Leinders-Zufall T, Kocsis JD. Retinal ganglion cells express a cGMP-gate cation concouctance activitable by nitric oxide donors. Neuron 1994;12:155-165.

21. Stamler JS..Redox signaling: Nitrosylation and related target interactions of nitric oxide. Cell 1994;78:931-936

22. Tilton RG, Chang K, Corbett JA., Misko TP, Currie MG, Bora NS, Kaplan HJ, Williamson JR. Endotoxininduced üveitis in the rat in attenuated by inhibition of nitric oxide production. Invest Ophthalmol Vsi Sci 1994;35:3278-3288.

23. Becquet F, Courtois Y, Goureau O. Nitric oxide decreases in vitro phagocytosis of photoreceptor outer segments by bovine retinal pigmented epithelial cells. J Cell Physiol 1994;159:259-262.

24. Furchgott RF, Zawadzki JV. The obligatory role of endothelial cells in the relaxation of arterial smooth muscle by acetylcholine. Nature 1980;288:373-376.

25. Rapoport RM, Murad F. Agonist-induced endotheliumdependent relaxation in rat thoracic aorta may be mediated through cGMP. Circ Res 1983;52:352-357.

26. Janssens SP, Shimouchi A, Quertermous T, Bloch DB, Bloch KD. Cloning and expression of a CDNA encoding human endothelium-derived relaxing factor/nitric oxide synthase. J Biol Chem 1992;267:14519-14522.

27. Shinde UA, Mehta AA, Goyal RK. Nitric oxide: A molecule of the millennium. Indian J Exp Biol 2000;38:201-210.

28. Alderton WK, Cooper CE, Knowles RG. Nitric oxide synthases: structure, function and inhibition. Biochem J 2001;357:593-615.

29. Govers R, Rabelink TJ. Cellular regulation of endothelial nitric oxide synthase. Am J Physiol 2001;280:193-206. 
30. Warpeha KM, Xu W, Liu L, et al. Genotyping and functional analysis of a polymorphic (CCTTT) ( $n$ ) repeat of NOS2A in diabetic retinopathy. FASEB J 1999; 13:1825-1832.

31. The Diabetes Control and Complications Trial Research Group. Clustering of long-term complications in families with diabetes in the Diabetes Control and Complications Trial. Diabetes 1997;46:1829-1839

32. Vailance $P$, Collier J. Biology and ciinical relevance of nitric oxide. Br Med J 1994; 309:453-457.

33. Ziche M. Role of nitric oxide in the angiogenesis of avascular tissue. Osteoarthritis Cartilage 1999;7:403405.

34. Monti LD, Valsecchi G, Costa S, et al. Effects of endothelin-I and nitric oxide on glucokinase activity in isolated rat hepatocytes. Metabolism 2000;49:73 -78

35. Piatti PM, Monti LD, Zavaroni I, et al. Alterations in nitric oxide/cyclic-GMP pathway in nondiabetic siblings of patients with type 2 diabetes. J Clin Endocrinol Metab 2000;85:2416-2420.

36. Wang XL, Mahaney MC, Sim AS, et al. Genetic contribution of endothelial constitutive nitric oxide synthase gene to plasma nitric oxide levels. Arterioscler Thromb Vasc Biol 1997;17:3147-3153.

37. Tsukada T, Yokoyama K, Arai T, et al. Evidence of association of the ecNOS gene polymorphism with plasma NO metabolite levels in humans. Biochem Bıophys Res Commun 1998;245:190-193.

38. Do Carmo A, Lopes C, Santos M, Proenca R, CunhaVaz J. Carvalho AP. Nitric oxide synthase activity and L-arginine metabolism in the retinas from streptozotocin-induced diabetic rats. Gen Pharmacol 1998;30:319-324.

39. Martin AR, Bailie JR, Robson T, et al. Retinal pericytes control expression of nitric oxide synthase and endothelin 1 in microvascular endothelial celis. Microvasc Res 2000;59:131-139.

40. Schmetterer L, Findl O, Fasching $P$, et al. Nitric oxide and ocular blood flow in patients with IDDM. Diabetes 1997;46:653-659.

41. Du Y.,Sarthy VP, Kern TS. Interaction between NO and COX pathways in retinal cells exposed to elevated glucose and retina of diabetic rats. Am. J. Physiol Regul Integr Comp Physiol 2004;287(4) :735-741

42. Kumaramanickavel G, Sripriya S, Vellanki RN, Upadyay NK, Badrinath SS, Rajendran V, Sukumar B, Ramprasad $\mathrm{VL}$, Sharma T. Inducible nitric oxide synthase gene and diabetic retinopathy in Asian Indian patients. Ciinical Genetics 2002;61:344-348.
43. Tesauro $M$, Thompson WC, Rogliani P, Qi L, Chaudhary PP, Moss J. Intracellular processing of endothelial nitric oxide synthase isoforms associated with differences in severity of cardiopulmonary diseases: cleavage of proteins with aspartate vs. glutamate at position 298. Proc Natl Acad Sci 2000;97:2832-2835.

44. Chan NN, Vallance P, Colhoun HM. Nitric oxide and vascular responses in type 1 diabetes. Diabetologia 2000;43:137-147

45. Klein R. Klein BE, Moss SE, Davis MD, De Mets DL. The Wisconsin epidemiologic study of diabetic retinopathy II. Prevalence and risk of diabetic retinopathy when age at diagnosis is less than 30 years. Arch Ophthalmol 1984;102:520-526.

46. Shibuki H, Katai N, Yodoi J. Uchida K. Yoshimura $\mathrm{N}$. Lipid peroxidation and peroxynitrite in retinal ischemia-reperfusion injury. Invest Ophthalmol Vis Sci 2000;41:3607-3614.

47. Hartnett ME, Stratton RD, Browne RW, Rosner BA, Lanham RJ, Armstrong D. Serum markers of oxidative stress and severity of diabetic retinopathy. Diabetes Care 2000;23:234-240.

48. Tilton RG, Chang KC, LeJeune WS, Stephan CC, Brock TA, Williamson JR. Role for nitric oxide in the hyperpermeability and hemodynamic changes induced by intravenous VEGF. Invest Ophthalmol Vis Sci 1999;40:689-696.

49. Brooks SE, Gu X, Samuel S, Marcus DM, Bartoli M, Huang PL et al. Reduced severity of oxygen-induced retinopathy in eNOS-deficient mice. Invest Ophthalmol Vis Sci 2001;42:222-228.

50. Sennlaub F, Courtois Y, Goureau O. Inducible nitric oxide synthase mediates the change from retinal to vitreal neovascularization in ischemic retinopathy. J Clin Invest 2001;6:717-725.

51. Kubes P, Suzuki M, Granger DN. Nitric oxide: an endogenous modulator of leukocyte adhesion. Proc Natl Acad Sci USA 1991;88:4651-4655.

52. Miyamoto K, Ogura Y: Pathogenetic potential of leukocytes in diabetic retinopathy. Semin Ophthalmol 1999;14:233-239.

53. Kubes P, GrangerDN. Nitric oxide modulates microvascular permeability. Am J Physiol 1992;262:611- 615.

54. He P, Zeng M, Curry FE. Effect of nitric oxide synthase inhibitors on basal microvessel permeability and endothelial cell (Ca2+)i. Am J Physiol 1997;273:747755.

55. Haverkamp S, Kolb H. Cuenca N. Endothelial nitric oxide synthase (eNOS) is localized to Muller cells in all vertebrate retinas. Vision Res 1999;39:2299-2303. 
56. Awata $T$, Neda T, lizuka $H$, Kurihara $S$, Ohkubo T, Takata N, Osaki M, Watanabe M, Nakashima Y, Sawa T, Inukai K, Inoue I, Shibuya M, Mori K, Yoneya S, Katayama S. Endothelial nitric oxide synthase gene is associated with diabetic macular edema in type 2 diabetes. Diabetes Care 2004;27:2184-2190.

57. Taverna MJ, Elgrably F, Selmi H, Selam JL. The T-786C and C774T endothelial nitric oxide synthase gene polymorphisms independently affect the onset pattern of severe diabetic retinopathy. Nitric Oxide 2005;13:88-92.

58. Cai $H$, Wang $X$, Colagiuri S, Wilcken DEL. A common Glu298Asp (894G-T) mutation at exon 7 of the endothelial nitric oxide synthase gene and vascular complications in type 2 diabetes. Diabetes Care 1998;21:2195.

59. Tso AW, Tan KC, Wat NM, Janus ED, Lam TH, S L Lam K. Endothelial nitric oxide synthase G894T (Glu298Asp) polymorphism was predictive of glycemic status in a 5-year prospective study of Chinese subjects with impaired glucose tolerance. Metabolism 2006;55:11551158.

60. Spinas GA. The dual role of nitric oxide in islet ß-cells. $N$ Physiol Sci 1999;14: 49-54.

61. Kobzik L, Stringer B, Balligand JL, Reid MB, Stamler JS. Endothelial type nitric oxide synthase in skeletal muscle fibers: mitochondrial relationships. Biochem Biophys Res Commun 1995;211:375-381.

62. Baron AD, Zhu JS, Irsula 0, Brechtel G, Keech C. Insulin resistance after hypertension induced by the nitric oxide synthesis inhibitor L-NMMA in rats. Am J Physiol Endocrinol Metab 1995;269:709-715.

63. Piatti PM, Monti LD, Zavaroni I, Valsecchi G, Van Phan C, Costa S, Conti M Sandoli EP, Solerte B, Pozza G, Pontiroli $A E$, Reaven G: Alteration in Nitric oxide/cycling-GMP pathway in nondiabetic siblings of patients with type 2 diabetes. J Clin Endocrinol Metab 2000;85:2416-2420.

64. Zavaroni I, Piatti PM, Monti LD, Gasparini P, Barilli LA, Massironi P, Ardigo D, Valsecchi G, Delsignore R, Raven GM. Plasma nitric oxide concentrations are elevated in insulin resistant healthy subjects. Metabo!ism 2000;49:959-961.

65. Ukkola O, Erkkila PH, Savolainen MJ, Kesaniemi YA. Lack of association between polymorphism of catalase, copper-zinc superoxide dismutase (SOD), extracellular SOD and endothelial nitric oxide synthase genes and macroangiopathy in patients with type 2 diabetes mellitus. J Int Med 2001 ;249: 451-459.

66. Patel A, Hibberd ML, Millward BA, Demaine AG. Chromosome 7q35 and susceptibility to diabetic microvascular complications. J Diabetes Complications 1996;10:62-67.

67. Neugebauer S, Baba T, Watanabe T. Association of the nitric oxide synthase gene polymorphism with an increased risk for progression to diabetic nephropathy in type 2 diabetes. Diabetes 2000;49:500-503.

68. Zanchi A, Moczulski DK, Hanna LS, Wantman M, Warram JH, Krolewski AS. Risk of advanced diabetic nephropathy in type 1 diabetes is associated with endothelial nitric oxide synthase gene polymorphism. Kidney Int 2000;57:405-413.

69. Weekers L, Hadjadj S, Belloum R, Gallois Y, Bouhanick $B$, Marre M. Lack of contribution of two endothelial nitric oxide synthase (eNOS) gene polymorphisms to diabetic nephropathy in type 1 diabetes. Diabetologia 1999;42:266.

70. Warpeha KM, Ah-Fat F, Harding S, Patterson CC, Xu W, Hart PM et al. Dinucleotide repeat polymorphisms in EDN1 and NOS3 are not associated with severe diabetic retinopathy in type 1 or type 2 diabetes. Eye 1999;13:174-178.

71. Tavakkoly-Bazzaz J, Boulton AJM, Pravica V, Hutchinson IV. eNOS gene

polymorphism in type 1 diabetes and its microangiopathic complications. Diabetes Metab 2003;29(Suppl2):S42.

72. Chen $\mathrm{Y}$, Huang $\mathrm{H}$, Zhou J, et al. Polymorphism of the endothelial nitric oxide synthase gene is associated with diabetic retinopathy in a cohort of West Africans. Mol Vis 2007;13:2142-2147.

73. Santos KG,Crispim D, Canani LH, et al. Relationship of endothelial nitric oxide synthase ( eNOS) gene polymorphisms with diabetic retinopathy in Caucasians with type 2 diabetes. Ophtalmic Genetics,2012;33(1) :23-27.

74. Cilensek I,Mankoc S,Petrovic MG, et al. The 4a/4a genotype of the VNTR polymorphism for endothelial nitric oxide synthase (eNOS) gene predicts risk for proliferative diabetic retinopathy in Slovenian patients ( Caucasians) with type 2 diabetes mellitus. Mol Biol Rep,2012

75. Suganthalakshmi B, Anand R, Kim R, et al. Association of VEGF and eNOS gene polymorphisms in type 2 diabetic retinopathy. Mol Vis 2006;12:336-341.

76. Uthra S, Raman R, Mukesh BN,et al. Intron 4 VNTR of endothelial nitric oxide synthase (eNOS) gene and diabetic retinopathy in type 2 patients in southern India. Ophtalmic Genet 2007;28:77-81. 